\title{
PUBLICIDADE CONTEMPORÂNEA: PRODUTIVIDADE DISCURSIVA E PROCESSOS DE SEDUÇÃO
}

\section{Contemporary advertising: Productivity and processes of seduction discursive}

\section{Publicidad contemporáneo: La productividad y los procesos del seducción de discurso}

\author{
Rosália Maria Netto Prados ${ }^{1}$ \\ Luci Mendes de Melo Bonini ${ }^{2}$
}

\section{Resumo}

Este trabalho trata de uma análise do discurso com base na Semiótica discursiva para o estudo de processos de produção de sentido nos textos de campanhas publicitárias contemporâneas. Propõe-se um estudo da produtividade discursiva no texto publicitário e seus efeitos de sentido, na constituição do sujeito contemporâneo na comunicação, além da análise e descrição dos discursos subjacentes ao texto publicitário. Para esta análise foi selecionada uma campanha, Johnnie Walker, apresentada na mídia em 2013.

Palavras-chave: discurso publicitário, produtividade discursiva, semiótica, sedução.

\begin{abstract}
This paper aims to analyze the contemporary advertising discourses using a Semiotic approach in order to study the process of the production of meaning. This study proposes a debate about discursive productivity in advertising texts and their meaning effects in the constitution of an individual beyond the analysis and description of the underlying texts of advertising discourses. For this purpose, it was selected the Johnnie Walker 2013, advertising series.
\end{abstract}

Key words: advertising discourse, discursive productivity, semiotics, seduction.

\section{Resumen}

${ }^{1}$ Doutora, pela FFLCH da USP em Semiótica e Linguística Geral, pós-doutora em Ciências da Comunicação, ECA-USP. Professora pesquisadora do programa de mestrado em Políticas Públicas da Universidade de Mogi das Cruzes. Email: rosalia.prados@gmail.com

${ }^{2}$ Doutora em Comunicação e Semiótica pela PUC-SP. Coordenadora do Mestrado em Políticas Públicas da Universidade de Mogi das Cruzes. Email: lucibonini@gmail.com 
En este trabajo se trata de un análisis del discurso basado en el estudio de los procesos de producción de significado en los textos de las campañas publicitarias actuales. Proponemos un estudio de la productividad discursiva en la publicidad y sus efectos de sentido, en la constitución del sujeto contemporáneo en la comunicación, más allá del análisis y descripción de los discursos publicitarios a lo texto subyacentes. Para este análisis hemos seleccionado una campaña, Johnnie Walker, presenta en los medios de comunicación en 2013.

Palabras-clave: discurso del publicidade, productividad del discurso, semiótica, seducción.

\section{INTRODUÇÃO}

Neste artigo, propõe-se uma reflexão sobre o discurso publicitário na cultura contemporânea, a partir de um estudo sobre os efeitos de sentido de sua produtividade discursiva na constituição do sujeito contemporâneo. Os discursos são processos de produção de sentidos que, por sua vez, manifestam-se por meio de linguagens verbais, não-verbais ou sincréticas nas diferentes situações de comunicação. Pretende-se analisar os universos discursivos e sistemas de valores veiculados pela publicidade no contexto cultural contemporâneo brasileiro. Esta pesquisa resultou de discussões propostas no grupo de pesquisa, Políticas Públicas em Educação, Formação Humana: desafios contemporâneos, sobre a constituição do sujeito contemporâneo na comunicação e interdiscursos na publicidade. Foi selecionada uma campanha publicitária, veiculada na mídia em 2013, a campanha do Johnnie Walker, que apresenta um sentimento de amor à pátria e apelo político, dado o contexto, momento em que se iniciavam mais intensivamente as chamadas para manifestações populares.

Propõe-se, assim, uma análise das relações intra e interdiscursivas do discurso publicitário, para se descrever os processos de sedução discursiva. São, portanto, objetivos deste trabalho, a análise e descrição das relações de interdiscursividade nos textos publicitários, por meio da análise das etapas do discurso, de acordo com a metodologia da Semiótica. Propõe-se uma análise do percurso narrativo do sentido desses discursos, ou seja, o percurso dos sujeitos em busca de seus objetos de valor e respectivos programas narrativos; uma análise da discursividade, ou seja, a tematização, figurativização, tempo e espaço; e, uma análise e descrição da semântica profunda, para o estudo da construção dos sistemas de valores dos sujeitos e das relações de linguagem, 
vistas como capacidade humana de discursos e suas contradições, bem como, dos processos de construção do 'saber social', ou seja, do saber compartilhado.

A Semiótica é a ciência que estuda, não só o universo dos signos, mas a significação. Não é possível, portanto, o estudo desta sem que se considere a transmissão, a conservação, a transformação e a aprendizagem da cultura que são processos que se realizam por meio das "práticas sociais" e que, por sua vez, organizam-se segundo "processos discursivos".

Para Bertrand (2003), esta Semiótica de linha francesa é apresentada como modelo de análise da significação, além da palavra, além da frase, na dimensão do discurso, tendo suas raízes na teoria da linguagem, e suas estruturas e concepções da língua como instituição social. O objeto da Semiótica é a descrição e análise das estruturas significantes que modelam o discurso social e o discurso individual. "A linha divisória está aqui definida: a palavra "signo" desapareceu; é que não se trata mais do signo, mas da significação" (Bertrand, 2003: 15).

O discurso, portanto, visto como capacidade humana de comunicação e como processo de construção do 'saber social', é o campo da Semiótica greimasiana, que tem por base o estudo da linguagem e concebe a língua como instituição social.

\section{O DISCURSO}

Parte-se da noção de que o discurso é um processo de produção de sentidos e o sujeito, em suas práticas sociais, é parte de uma engrenagem: a da produtividade discursiva. Para se entender essa noção, considere-se antes a seguinte concepção de discurso:

\footnotetext{
quando se escolhe como ponto de partida o discurso, dá-se conta rapidamente de que formas cristalizadas ou convencionais que nele encontramos estão longe de serem unicamente signos, pois uma das propriedades mais interessantes do discurso é a sua capacidade em esquematizar globalmente nossas representações e nossas experiências. Do mesmo modo, o estudo dos esquemas do discurso toma rapidamente o lugar do estudo dos signos propriamente ditos. (FONTANILLE, 2008: 83).
}

Desta maneira, o discurso é considerado como resultado de uma expressão humana que produz sentidos, representações e experiências. As ideias de Fontanille têm base na linha teórica francesa de análise de discurso. Este, portanto, refere-se à Semiótica, protagonizada por Greimas (2001), que tem por base a teoria da linguagem 
para se analisar o percurso do sentido que subjaz ao texto. Esta análise semiótica do discurso se dá por meio da desconstrução de suas estruturas, pois a existência das "coisas" somente faz sentido por meio da produção de um discurso que lhes atribui significados, ou seja, o discurso é que produz o sentido.

Segundo Pais (2005), há uma articulação entre o saber e a significação no processo de produção discursiva e reflete sistemas de valores de uma comunidade, pois a visão de mundo de uma comunidade sociocultural e linguística, bem como sua ideologia, acha-se sempre em processo de (re)formulação e um constante processo de vir a ser que, segundo Pais, paradoxalmente, transmite a seus membros o sentido de estabilidade e de continuidade.

Dessa maneira, para Pais (2005), um mesmo discurso pode pertencer simultaneamente a mais de um universo de discurso, caracterizando-se assim a interdiscursividade. Um discurso publicitário, por exemplo, pode estar inserido num universo de discurso político, feminino, científico ou mesmo educacional.

As linguagens que caracterizam a rede de comunicação, em que se mantém o sujeito contemporâneo, apresentam universos de discursos que refletem os sistemas de valores, como exercício pleno da cidadania, do consumo, da felicidade ou da saúde, por exemplo. Neste caso, a referida campanha traz universos discursivos jornalísticos que veicularam na mídia em 2013, o aumento da passagem do transporte público em São Paulo, obras sem licitação para a Copa de Futebol 2014, dentre outras informações.

Segundo Pais (2007), ao longo do processo histórico, a migração de indivíduos e de grupos decorre do esforço incessante do homem, em busca da sobrevivência ou de melhores condições de vida. Fugir de situações políticas insuportáveis e procurar qualificação profissional, ou inserção no mercado de trabalho, ou busca de justiça social incentivam o deslocamento de pessoas em correntes que se intensificam nos dias atuais. O convívio de grupos humanos de culturas diferentes, que sustentam sistemas de valores e visões de mundo distintas, conflitantes, no plano da ética, dos usos e das aspirações, caracteriza o contexto brasileiro contemporâneo e justificam a constituição de universos discursivos das manifestações populares, da inclusão social e do exercício da cidadania, por exemplo.

\section{DISCURSO PUBLICITÁRIO: PERSPECTIVA SOCIOSSEMIÓTICA}


A Sociossemiótica, uma especificidade da Semiótica discursiva, estuda os discursos sociais não-literários, tais como, os discursos científico, tecnológico, político, jurídico, jornalístico, publicitário, pedagógico, burocrático, religioso, dentre outros. É vista como ciência, cuja abordagem trata da apreensão do sentido, enquanto dimensão provada do ser no mundo, ou seja, o sentido em ato, construído no momento da interação, nas diferentes práticas sociais e discursivas (PRADOS, 2006).

Esses universos de discurso são ditos sociais, porque, embora tenham, como é evidente, na textualidade, emissor e receptor individuais, caracterizam-se na discursividade o enunciador e enunciatário coletivos. São discursos produzidos por um grupo ou segmento social, uma instituição ou um partido político, os legisladores, a comunidade científica, entre outros. Diz-se que são discursos não literários, porque a função estética, embora, nesses discursos exista com características específicas, não é determinante de sua eficácia, nem de seu estatuto sociossemiótico, que é conferido pela sociedade (PAIS, 2005).

O estudo do discurso publicitário e de propaganda é objeto da Sociossemiótica, pois os textos nas campanhas publicitárias ou de propaganda têm uma função estética com características específicas. Nesses textos, a sedução discursiva do texto publicitário consiste-se segundo os critérios da verossimilhança, tais como no texto literário, apesar do discurso publicitário se inserir no campo de análise da Sociossemiótica, que estuda discursos não literários, pois tem enunciador e enunciatário coletivos. O sujeito coletivo está indefinidamente em construção, uma vez que, "a alteridade do Outro é um dos elementos da identidade do Nós" (LANDOWSKI,1992:23).

Para Landowski (1992), a Sociossemiótica, trata não só do estudo da terminologia e das figuras, por meio das quais se exprime a diversidade das posições sociais e dos interesses em jogo nos discursos, mas também da questão do funcionamento global e da eficácia social dessa atividade discursiva enquanto tal.

Bertrand (2003) considera o texto literário propriamente dito como um todo de significações que produz condições contextuais de sua leitura, e que o texto dito literário, diferente dos outros textos, incorpora seu contexto e contém em si mesmo o seu código semântico atualizado por seu leitor, indiferente das intenções do seu autor, trazendo condições de ser legitimado. Assim tornando o sentido de um texto autônomo em relação à intenção subjetiva de seu autor, tendo como essencial desdobrar o texto diante do mundo que abre e descobre como sujeito. 
Esta produtividade no discurso, de acordo com a abordagem da Semiótica francesa, é entendida como relação de dependência entre o plano do conteúdo e o plano da expressão (HJELMSLEV, 2006); ou entendida como produção de informação, ou recortes culturais; e como produção e sustentação de ideologia ou sistemas de valores (PAIS, 2005).

A metodologia de análise, segundo essa perspectiva da Sociossemiótica, trata da análise do percurso gerativo do sentido, para descrever, sobretudo, a axiologia, ou seja, os microssistemas de valores sustentados, ou o saber social, no nível da semântica profunda. De acordo com Greimas (2001), no discurso, as estruturas narrativas podem ser reconhecidas em manifestações do sentido aceitando-se a necessidade de uma distinção fundamental entre dois níveis de representação e de análise: um nível aparente da narração, em que as diversas manifestações desta se submetem às exigências específicas das substâncias linguísticas por meio das quais ela se exprime; e um nível imanente, que constitui uma espécie de tronco estrutural comum, em que a narratividade se encontra situada e organizada anteriormente à sua manifestação. Nesse processo de produtividade discursiva, um nível semiótico comum se distingue, portanto, de um nível linguístico, da manifestação, e lhe é logicamente anterior.

Segundo essa metodologia, a partir da descrição de modalidades discursivas, que correspondem a metatermos (enquanto termos de uma metalinguagem), numa etapa narrativa do discurso, modelos de análise dos valores manifestados nos discursos foram desenvolvidos; são modelos formalizados com base no saber compartilhado sobre o mundo pelos membros de determinada comunidade e que integram seu imaginário, ou seja, sua cultura, ou, segundo Pais (2007) é um mundo semioticamente construído.

\section{PRODUTIVIDADE DISCURSIVA E A PUBLICIDADE}

Segundo esta análise do discurso publicitário contemporâneo, evidencia-se um processo de produção de sentido que difunde e reflete sistemas de valores da sociedade contemporânea. Primeiramente, na campanha da bebida, o whisky Johnnie Walker, de acordo com o percurso que gera o sentido, manifesta-se um discurso. De acordo com a metodologia sociossemiótica, esse discurso publicitário, em sua etapa narrativa, apresenta um estado inicial em que um sujeito, o Destinador manipulador, Brasileiro Contemporâneo1 - sujeito coletivo que não aceita o aumento da passagem - instaura um 
sujeito Destinatário, o Brasileiro2 - o sujeito coletivo passivo, que aceita as imposições que se lhe surgem - e que passa a querer um Objeto de Valor, que é o Despertar.

Nesse texto publicitário fílmico não-verbal, vê-se o Pão de Açúcar se levantando diante das pessoas e em torno das grandes cidades brasileiras, o chão se eleva e um gigante caminha, surpreendendo as pessoas e aparece um enunciado verbal o gigante acordou. Só então aparece a marca e, rapidamente, o alerta da Secretaria da Saúde.

Esta campanha foi veiculada no período em que, no contexto social brasileiro, apareciam as grandes manifestações populares que adquiriram força na luta pela diminuição do preço do transporte urbano em São Paulo e, depois se generalizaram e se espalharam por todo o país.

De acordo com a análise semiótica, Estado Inicial, Ação/Transformação e Estado Final, caracteriza-se pelo discurso, uma ação/transformação, pois o Sujeito estava em disjunção com o Objeto de Valor - passivo dormindo - e no Estado Final, o Sujeito alcança seu Objeto de Valor, que é o Despertar.

Apresenta-se encoberto pela figura, despertar, um discurso político. Segundo Landowski (1992), há uma lógica que constitui um dos motivos mais constantes e poderosos da dinâmica desse discurso, que é mais profunda e de alcance mais geral, subjacente a todo desejo de renovação, em toda a esperança de transformação do presente, que provém antes do desejo do que da vontade ou da necessidade. Ou seja, para se compreender a que se deve a força dos movimentos de opinião que apoiam ou apelam com uma insistência particular para o aparecimento da mudança em política, é necessário considerar que esses movimentos não se detêm apenas à racionalidade de um homo politicus ideal, com justos argumentos que o levem a agir, para transformar o mundo e torná-lo um mundo melhor. Mas, segundo Landowski (1992), tais movimentos políticos têm origem em algo que tem relação com a gestão do sentimento de identidade do sujeito coletivo, atores ou testemunhos do que muda em torno deles e com eles.

O desejo de mudança, para Landowski (1992), não é apenas uma tomada de posição diante de coisas que mudam, ou que se gostaria que melhorassem, mas também escolher uma maneira determinada de viver seu próprio devir, ou seja, de colocar-se em condição de desfrutar o tempo presente, qualquer que seja este, percebendo a si mesmo como imediatamente inscrito no movimento do momento que passa, como participante do desenrolar de uma atualidade vivida em comum com outrem, compartilhada, efetivamente presente a si mesmo. 
Dessa maneira, a mudança torna-se produtora de identidade. Não se trata de, ao aderir à mudança, deixar de ser alguém, ou deixar de apresentar ideias como se apresentava antes, mas, segundo Landowski (1992), é um dos meios mais elementares de afirmar sua própria existência, tanto o olhar de si mesmo como diante de outrem. É mudar não só a vida, em todo o caso, mas o sentido de sua própria vida.

Esse contexto sociocultural, por meio do qual os sujeitos se identificam, caracteriza-se como uma macrossemiótica, segundo Pais (2005), uma sociedade e uma cultura são determinantes para o mundo semioticamente construído. Nesse texto publicitário, é possível verificar-se a interdiscursividade e intertextualidade, numa intersemiose com o Hino Nacional, em trechos como,

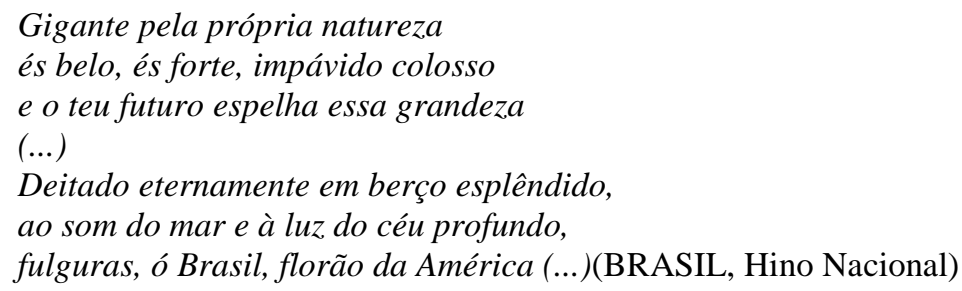

Essa visão de mundo construída semioticamente é o conjunto de todas as semióticas-objeto e seus discursos dentro da comunidade sociocultural que, segundo Pais (2005), realimentam-se, pois tais discursos são dotados de auto-regulagem, de acordo com Pais, e alimentam outros sistemas: o sistema cultural que vai autorizar um fazer-cultural e um fazer-social.

Essa imagem do gigante adormecido, que desperta surpreendendo a todos, é inicialmente a figura de um livro, As Viagens de Gulliver, de Jonathan Swift (2010), é uma obra literária de 1726 com forte teor político. O gigante está adormecido, por isso é amarrado pelos habitantes, mas ao despertar, liberta-se. É uma figura que reforça a ideia de que o despertar liberta, de que o saber liberta, dentre outras metáforas dessa obra.

Nessa análise da narrativa mínima do discurso manifestado nesse texto publicitário verifica-se que o texto tem em sua estrutura superficial, um percurso figurativo, O Gigante Acordou, que concretiza os valores Passividade X Participação, que estão no nível profundo do discurso e caracterizam o contexto sociocultural do período do início das grandes manifestações por conquistas sociais no atual quadro político. Nesse contexto de sentimento de orgulho pela participação coletiva, insere-se o produto: é um discurso sedutor que relaciona o prazer da liberdade à bebida, ao wisky 
Johnnie Walker. Há um reforço da marca, o cavalheiro caminhando e o gigante que acordou, na estrutura superficial da discursividade.

A narratividade desse discurso constitui-se por essa sintaxe. Em Semiótica, dizse funções sintáxicas e não sintáticas, pois o termo refere-se a uma gramática do texto e não ao funcionamento no nível da frase. Fica definida uma tensão sistema/discurso para sustentar a permanência e funcionamento de um processo semiótico, pois os sistemas semióticos fundam-se em relações de significação e semiose permanente.

O modelo de análise proposto por Pais (2005), do percurso gerativo da enunciação de codificação e enunciação de decodificação, é considerado como um ciclo completo do processo de enunciação em que se alternam o fazer persuasivo (do sujeito enunciador) e o fazer interpretativo (do sujeito enunciatário). Assim, no dizer de Pais (2005), todos os termos que compõem a competência do sujeito enunciadorenunciatário do discurso constituem elementos determinantes do desempenho, são elementos determinantes das condições semióticas da produtividade sistêmica, lexical e discursiva.

Dessa maneira, explicou o processo de produção do discurso a partir do sistema (competência autoriza o desempenho) e a produção, reiteração, transformação dos recortes e das significações que os manifestam em discurso como também a produção de novo estágio do sistema ou a modificação da competência decorrente da produção de discurso ao longo da história da sociedade e cada um de seus membros, numa relação dialética.

Nesse discurso publicitário, no nível da semântica profunda, verifica-se um reforço dos valores de consumo na sociedade contemporânea, que pode ser formalizada de acordo com um modelo de Pais (2001).

Para Pais (2001), há uma tensão dialética que se sustenta entre o sistema cultural e o metassistema conceptual, aquele que está no nível anterior à manifestação discursiva, que define a informação de conteúdo dos processos semióticos envolvidos. Assim a produção de informação é "indissociável" da produção de significação. Esta, entendida como função semiótica, é a relação de dependência entre um plano de conteúdo e um plano de expressão resultante da semiose e define-se, em determinado processo semiótico como uma tensão significante/significado.

Segundo a Sociossemiótica, Pais desenvolveu vários modelos muito produtivos de análise do discurso, são octógonos semióticos produzidos a partir do modelo de análise do percurso do sentido, o quadrado semiótico, para o estudo dos discursos que 
Publicidade contemporânea: Produtividade discursiva e processos de sedução

de Rosália Maria Netto Prados e Luci Mendes de Melo Bonini

circulam no cenário sociocultural brasileiro contemporâneo, como o abaixo descrito, por exemplo:

Fig. 1 - Universo do Discurso: consumo x convívio Fonte: Pais, 2001: 187

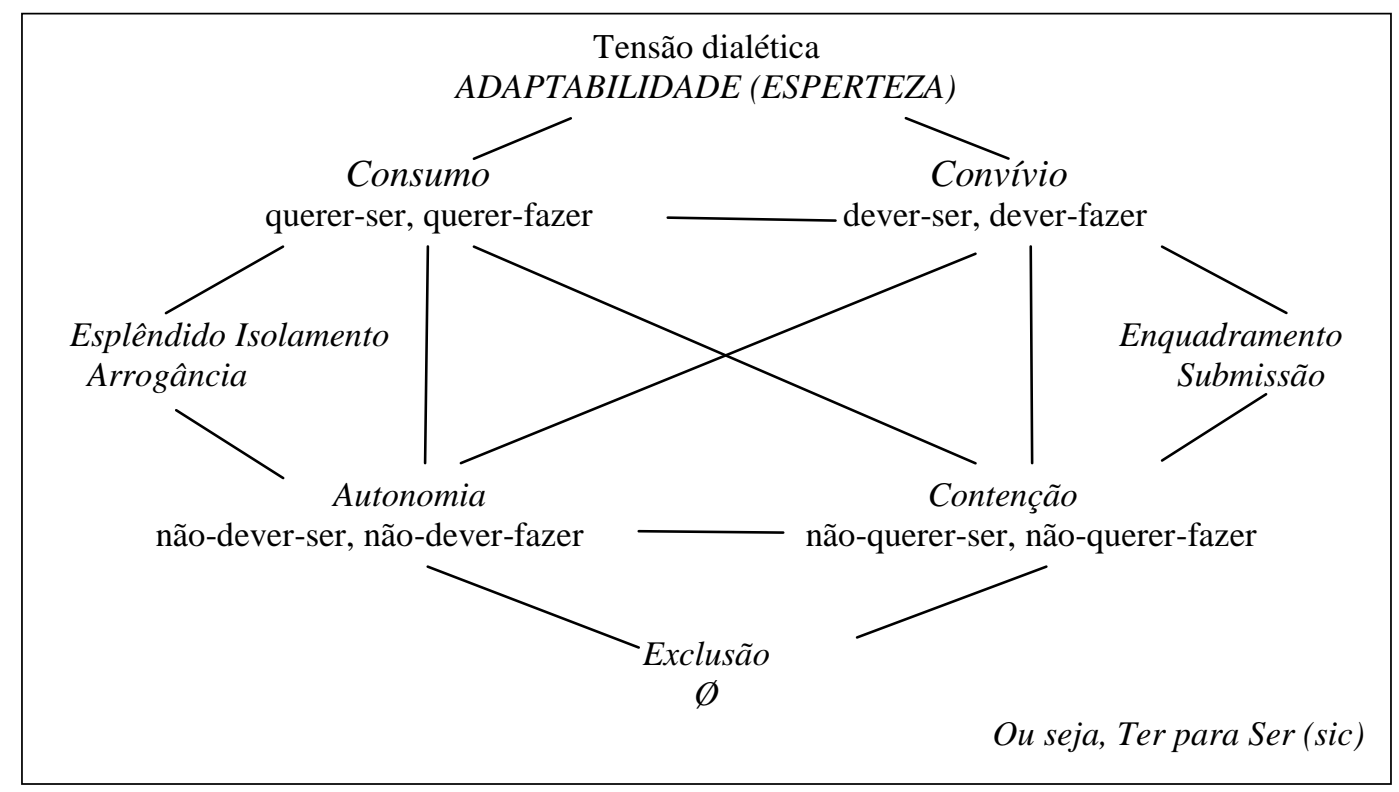

Segundo esta análise da campanha Johnnie Walker, é possível a descrição de valores do discurso publicitário que refletem o contexto em que se caracteriza o sentimento de orgulho pelas lutas, mas também que reforçam a marca e o apelo para o consumo. Segundo esta leitura semiótica, para Pais, estabelece-se, pois, uma tensão dialética entre duas tendências contrárias, o desejo de consumo, definido pela combinatória modal [querer-ser e querer-fazer], e a necessidade convívio com o diferente, caracterizado pelas modalidades [dever-ser e dever-fazer], entre o prazer e o dever. O termo contraditório de convívio é autonomia, definido, por sua vez, pela combinatória modal [não-dever-não-ser e não-dever-não-fazer]; o contraditório de consumo é contenção, a que correspondem as modalidades [não-querer-ser e nãoquerer-fazer].

Nessas condições, o epicentro da tensão, o lugar do conflito e do equilíbrio dinâmico, pode ser manifestado pelo metatermo adaptabilidade, um equivalente da esperteza, qualificada como [querer-ser e querer-fazer x dever-ser e dever-fazer]. Segundo Pais (2001: 186-188), no plano lógico, está a combinação entre autonomia e consumo e pode ser manifestada pelo metatermo esplêndido insolamento, um [querer- 
Publicidade contemporânea: Produtividade discursiva e processos de sedução

de Rosália Maria Netto Prados e Luci Mendes de Melo Bonini

ser e querer-fazer x não-dever-não-ser e não-dever-não-fazer], podendo ser equivalente à arrogância. Estado em que se encontra a classe que consome.

De outro lado, está o enquadramento que decorre da combinação de convívio e contenção, um [dever-ser e dever-fazer x não-querer-ser e não-querer-fazer], de certa forma equivalente à submissão. Da combinação de autonomia e contenção advém o termo neutro, um [não-dever-não-ser e não-dever-não-fazer x não-querer-ser e nãoquerer-fazer], que estabelece a situação de exclusão (Pais, 2001: 187).

Essa é uma descrição da semântica hiper-profunda, segundo Pais, da produtividade discursiva de diferentes universos de discursos num contexto sociocultural e que descreve os sistemas de valores que subjazem ao texto publicitário da campanha do whisky Johnnie Walker.

\section{CONSIDERAÇÕES FINAIS}

O sujeito faz parte de uma comunidade sociocultural, é um ser social, cultural e histórico. Identifica-se com saberes e valores compartilhados pelo grupo, por uma visão de mundo, por um imaginário coletivo. Segundo Pais (2005), esses valores e saberes habilitam ao convívio social e conferem aos membros do grupo a sua identidade cultural, a sua memória social, a consciência da sua pertinência ao grupo e de sua continuidade no tempo.

Por meio dessa análise, pôde-se verificar que no nível superficial do texto fílmico da campanha publicitária do Johnnie Walker, caracteriza-se a interdiscursividade, que pode ser descrita segundo o percurso do sentido no texto. A combinatória de processos significativos, ou unidades de significação, inscritas na linguagem desse enunciado, O Gigante Acordou, possibilitou "efeitos de sentido", que, por sua vez, conforme o contexto produziu leituras e interpretações. Estas caracterizam a estrutura profunda do discurso veiculado no texto do enunciado, revelando os microssistemas de valores manifestados na mídia em 2013.

\section{REFERÊNCIAS BIBLIOGRÁFICAS}

BERTRAND, Denis. Caminhos da Semiótica literária. Bauru, SP: ESDUSC, 2003. 
Publicidade contemporânea: Produtividade discursiva e processos de sedução

de Rosália Maria Netto Prados e Luci Mendes de Melo Bonini

BRASIL. Letra do Hino Nacional Brasileiro. Disponível em < http://www.pm.ba.gov.br/Hinos/Letras/HinoNacionalBrasileiro.pdf> Acesso em 12 de março de 2014.

GREIMAS, A. J. Del Sentido II. Ensaios semioticos. Madrid: Gredos, 2001.

HEJLMSLEV, L.T. Prolegômenos a uma teoria da linguagem. São Paulo: Perspectiva, 2006.

LANDOWSKY, Eric. A Sociedade Refletida. São Paulo: EDUC editora da PUC, 1992.

PAIS, C.T. Ciência, Tecnologia, Educação Institucional face a questões suscitadas pela globalização e pela diversidade cultural. In. Revista Brasileira de Linguística. Vol. 11. Ano 27. São Paulo: $3^{\mathrm{a}}$ Margem, 2001: 185-197.

- Propaganda e Publicidade no interdiscurso. Os sujeitos dos discursos científico e tecnológico em busca de seus objetos de valor. In Revista Philologus. Ano 11, no 31. Rio de Janeiro:CIFEFIL, jan/abril, 2005.

. Considerações sobre a Semiótica das Culturas, uma ciência da interpretação: inserção cultural, transcodificações transculturais. In. Acta Semiótica et Linguistica. Vol. 11. Ano 30. São Paulo: $3^{\text {a }}$ Margem, 2007: 149-157.

PRADOS, Rosália M.N. O discurso publicitário e a construção da imagem dos sujeitos nos discursos político-eleitorais: um estudo à luz da Sociossemiótica. Relatório de Pós-Doutorado apresentado ao Departamento de Relações Públicas, Propaganda e Turismo, da Escola de Comunicações e Artes, da Universidade de São Paulo, Área de Ciências da Comunicação. USP, Universidade de São Paulo, São Paulo, 2006.

SWIFT, Jonathan. As Viagens de Gulliver. Trad. Paulo Henriques Britto. São Paulo: Companhia das Letras, 2010.

Artigo submetido: 27/05/2014

Artigo aprovado: 09/11/2014 